\title{
若尔盖地区晚白严世以来隆升作用与流体活动 耦合效应
}

\author{
邓宾，刘树根 ${ }^{*}$ ，李巨初，王国芝，刘顺，李智武，李祥辉 \\ 成都理工大学油气藏地质及开发工程国家重点实验室, 成都 610059 \\ * 联系人, E-mail: 1sg@cdut.edu.cn
}

收稿日期: 2009-10-28; 接受日期: 2010-09-07

\begin{abstract}
摘要若尔盖地区晚白严世以来阶段性隆升幅度不少于 $3400 \mathrm{~m}$, 晚白严世和晚中新世至今阶 段的快速隆升过程对本区流体应力场产生了重要的影响. 综合野外详细地质、裂缝系统空间分 布和流体包裹体地球化学等特征研究表明, 若尔盖地区浅部地层以发育高角度(或近垂直)裂缝 为主, 深部地层以发育低角度(或近平行)裂缝为主; 流体早期具有热流体增温特征, 中、晚期具 有淡水流体混合特征, 多期流体混染形成开放性流体动力环境, 阶段性快速抬升过程与流体活 动的多期性特征具有一定对应性. 基于阶段性隆升过程诱发的岩石应力-应变行为特征, 讨论了 本区多期隆升运动背景下, 阶段性隆升释压与流体幕式流动的时空耦合机制及油气地质效应.
\end{abstract}

关键词

阶段性隆升 古流体 隆升释压 幕式流动 若尔盖地区
抬升剥蚀是我国西部含油气盆地普遍存在的事 实, 对油气晚期成藏存在着建设性的影响 ${ }^{[1 \sim 5]}$, 可以 说隆升是西部地区晚期成藏的根本动力. 大规模流 体活动是油气成藏过程各环节的关键和主要控制因 素, 因而对流体活动研究是认识和预测油气分布规 律以及指导油气勘探方向的重要途径之一 ${ }^{[6-8]}$, 而对 隆升过程中流体行为特征的研究更有助于对油气的 动态分布和聚集状态的深入了解 ${ }^{[2 \sim 4,9,10]}$. 但是多期隆 升的叠加作用对流体运移动力学的影响机理及其过程, 尤其是复杂构造运动地区多期隆升对流体(油气)运移 的动态控制作用, 是当前学科研究的前沿与难点.

若尔盖地区地处松潘-甘孜褶皱带北部, 晚三叠 世至今经历了盆(沉积盆地)-山(造山带)-原(高原)-盆 (第四系盆地) 的演化过程 ${ }^{[113]}$, 尤其是中新世以 来 $^{[14 \sim 17]}$ 的造原过程导致整个川西高原的区域抬升,
对全区流体能量场的改变产生了至关重要的作用. 基于地表磷灰石裂变径迹热年代学反演若尔盖地区 的热隆升过程, 给流体运移的动态演化及各种与其 相关的热流事件鉴别提供了框架; 反之，对流体作用 和现象的历史分析及对流体自身形成和演化的反演, 可以较细致地重建隆升历史与流体活动的时空耦合 效应. 本文通过分析若尔盖地区构造脉体空间分布 和流体包裹体特征变化(以 HC-1 井垂向空间特征变 化为重点), 结合中、新生代热隆升过程的反演, 初步 探讨若尔盖地区阶段性隆升与流体运移的耦合关系 及其油气地质效应.

\section{1 若尔盖地区晚白严世以来隆升作用}

若尔盖地区位于松潘-甘孜褶坡带东北部，与西

英文引用格式: Deng B, Liu S G, Li J C, et al. The coupling of fluid flow and uplift since Late Cretaceous in Zoige area, western Sichuan. Sci China Earth Sci, 2011, doi: $10.1007 / \mathrm{s} 11430-011-4185-2$ 
秦岭南缘造山带比邻, 中-晚三叠世印支主碰撞期中 央造山带由东向西穿时碰撞闭合完成中国南北大陆 主体拼合，松潘-甘孜地区也发生了区域褶皱造 $山^{[11 \sim 13]}$, 中-上三叠统复理石发生复杂构造变形. 若 尔盖地区地表出露主要为晚三叠世杂古脑组、侏倭组 和新都桥组复理石沉积地层, 中新生代地层普遍缺 失, 仅在其北部地区断陷盆地零星出露 ${ }^{[18]}$. 唐克-若 尔盖地区侏倭组岩性为灰绿色或褐灰色凝灰质长石
石英砂岩、岩屑砂岩与砂质板岩互层, 新都桥组岩性 为深灰色千枚状板岩夹黄色薄层-厚层长英质岩屑细 砂岩. 沿若尔盖-唐克省道公路 HC-1 井地区对地表上 三叠统新都桥组和杂古脑组中岩屑砂岩进行系统新 鲜样品的采集(图 1), 选样后在中国科学院高能物理 研究所进行了样品的磷灰石裂变径迹外探测器法测 试(见表 1). 所有样品单颗粒年龄远小于地层年龄

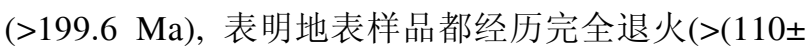

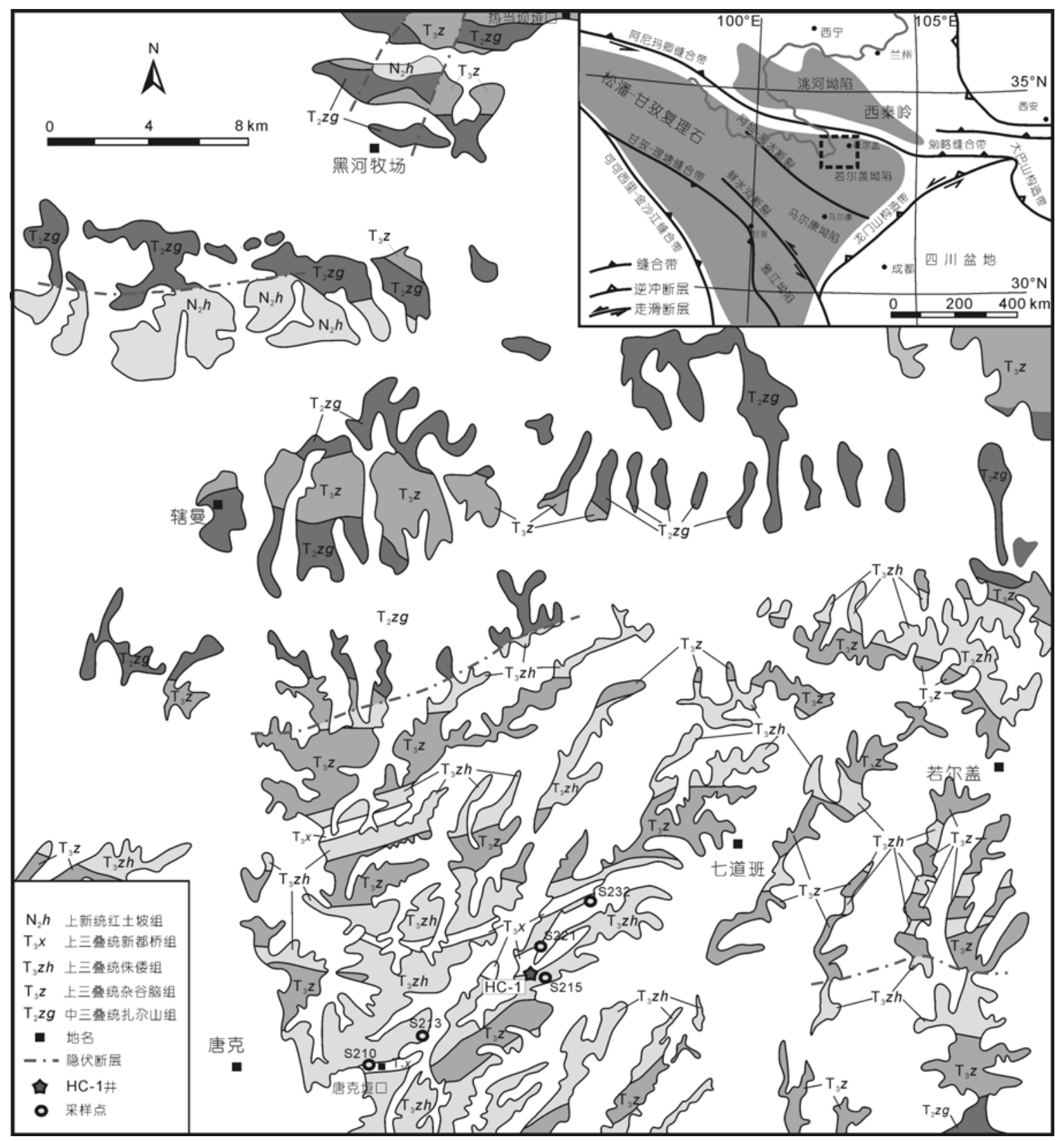

图 1 若尔盖地区区域地质简图及研究背景 
表 1 若尔盖地区样品磷灰石裂变径迹分析结果 ${ }^{\text {a) }}$

\begin{tabular}{|c|c|c|c|c|c|c|c|c|c|c|}
\hline 样号 & GPS 点 & 地层 & 岩性 & $\begin{array}{l}\begin{array}{l}\text { 高程 } \\
(\mathrm{m})\end{array} \\
\end{array}$ & 颗粒数 & $\begin{array}{c}\rho_{\mathrm{s}}\left(10^{5} \mathrm{~cm}^{-1}\right) \\
\left(N_{\mathrm{s}}\right)\end{array}$ & $\begin{array}{c}\rho_{\mathrm{i}}\left(10^{5} \mathrm{~cm}^{-1}\right) \\
\left(N_{\mathrm{i}}\right)\end{array}$ & $P\left(\chi^{2}\right) \%$ & $\begin{array}{c}\text { 中值年龄 } \pm 1 \sigma \\
(\mathrm{Ma})\end{array}$ & $\begin{array}{l}L(\mu \mathrm{m}) \\
(N) \\
\end{array}$ \\
\hline S210 & $\begin{array}{c}33^{\circ} 24^{\prime} 53.2^{\prime \prime} \mathrm{N} \\
102^{\circ} 33^{\prime} 36.7^{\prime \prime} \mathrm{E}\end{array}$ & $\mathrm{T}_{3} z$ & 砂岩 & 3578 & 26 & $\begin{array}{l}1.714 \\
(265)\end{array}$ & $\begin{array}{l}11.372 \\
(1758)\end{array}$ & 99.5 & $50 \pm 4$ & $\begin{array}{c}13.1 \pm 1.8 \\
(92)\end{array}$ \\
\hline S213 & $\begin{array}{c}33^{\circ} 25^{\prime} \cdot 6^{\prime \prime} \mathrm{N} \\
102^{\circ} 34^{\prime} 48.8^{\prime \prime} \mathrm{E}\end{array}$ & $\mathrm{T}_{3} z$ & 砂岩 & 3510 & 25 & $\begin{array}{l}1.731 \\
(407)\end{array}$ & $\begin{array}{l}8.427 \\
(1981)\end{array}$ & 68.7 & $68 \pm 5$ & $\begin{array}{c}12.7 \pm 1.9 \\
(106)\end{array}$ \\
\hline S215 & $\begin{array}{c}33^{\circ} 27^{\prime} 34.0^{\prime \prime} \mathrm{N} \\
102^{\circ} 39^{\prime} 00.5^{\prime \prime} \mathrm{E}\end{array}$ & $\mathrm{T}_{3} z$ & 砂岩 & 3480 & 22 & $\begin{array}{l}2.446 \\
(334)\end{array}$ & $\begin{array}{l}12.076 \\
(1649)\end{array}$ & 98.4 & $67 \pm 5$ & $\begin{array}{c}12.5 \pm 1.8 \\
(106)\end{array}$ \\
\hline S221 & $\begin{array}{c}33^{\circ} 28^{\prime} 42.3^{\prime \prime} \mathrm{N} \\
102^{\circ} 39^{\prime} 36.6^{\prime \prime} \mathrm{E}\end{array}$ & $\mathrm{T}_{3} x$ & 砂岩 & 3506 & 21 & $\begin{array}{l}1.785 \\
(399)\end{array}$ & $\begin{array}{l}9.629 \\
(2153)\end{array}$ & 82.0 & $61 \pm 4$ & $\begin{array}{c}12.2 \pm 1.8 \\
(100)\end{array}$ \\
\hline S232 & $\begin{array}{c}33^{\circ} 29^{\prime} 25.9^{\prime \prime} \mathrm{N} \\
102^{\circ} 40^{\prime} 11.9^{\prime \prime} \mathrm{E}\end{array}$ & $\mathrm{T}_{3} z$ & 砂岩 & 3482 & 23 & $\begin{array}{l}1.448 \\
(272)\end{array}$ & $\begin{array}{l}7.803 \\
(1466)\end{array}$ & 45.8 & $61 \pm 5$ & $\begin{array}{c}13.4 \pm 1.5 \\
(109)\end{array}$ \\
\hline
\end{tabular}

a) $\rho_{\mathrm{s}}$, 自发径迹密度; $N_{\mathrm{s}}$, 自发径迹条数; $\rho_{\mathrm{l}}$, 诱发径迹密度; $N_{\mathrm{i}}$, 诱发径迹条数; $P\left(\chi^{2}\right)$, 检验概率; 中值年龄 $\pm 1 \sigma$, 径迹年龄标准差; $L$, 径迹长度; $N$, 封闭径迹条数; 样品由中国科学院高能物理研究所测试

$\left.10)^{\circ} \mathrm{C}\right)$ ，单颗粒年龄 $\chi^{2}$ 检验值 $P\left(\chi^{2}\right)$ 为 $45.8 \% ~ 99.5 \%$, 远远大于同组年龄检验值 $5 \%$, 表明各样品单颗粒年 龄差别属于系统误差, 具有单一的年龄平均值, 样品 颗粒径迹年龄可以视为同组年龄, 样品中值年龄为 $(50 \pm 4) \sim(68 \pm 5)$ Ma. 样品裂变径迹长度 $(12.2 \pm 1.8) \sim$ $(13.4 \pm 1.5) \mu \mathrm{m}$ 都远小于原始径迹长度 $(16.3 \pm 0.9) \mu \mathrm{m}$, 表明样品都经历过显著的抬升冷却退火过程.

基于裂变径迹分析测试数据, 应用 Ketcham 退 火模型和蒙特卡罗逼近法以及 AFTSOLVE 模拟软 件 ${ }^{[19]}$, 结合区域地质背景确定反演模拟的初始条件, 对磷灰石裂变径迹样品的时间-温度热隆升史进行定 量模拟(图 2). 所有样品在 100 70 Ma 和 $25 \mathrm{Ma}$ 至今 两个阶段发生显著快速隆升过程(图 2(b)和(c)), 距今 70 25 Ma 阶段各样品呈差异抬升特征, 总体处于缓 慢抬升过程, 晚期快速抬升中不同样品退火时间各 不相同(50 25 Ma), 其反映的差异构造快速隆升时间 应与区内不同断块的差异隆升活动相关. 结合热史 模拟温度-时间曲线 $(T-t)$ 与区域地温梯度(设地温梯度 为 $32.1^{\circ} \mathrm{C} \mathrm{km}$, 地表温度为 $10^{\circ} \mathrm{C}$ ), 可以定量得到各 样品阶段性热隆升速率 ${ }^{[2,16,17]}$. 各样品模拟热隆升史 表明(图 2(a)), 若尔盖地区具有阶段性隆升特征, 阶 段式隆升总幅度不低于 $3400 \mathrm{~m}$, 晚白严世快速隆升 期(95 70 Ma)平均抬升速率和平均隆升幅度分别为 $76 \mathrm{~m} \mathrm{Ma}^{-1}$ 和 $1300 \mathrm{~m}$; 距今 70 20 Ma 为缓慢隆升阶 段, 构造抬升运动趋于平缓 (平均抬升速率和隆升幅 度分别为 $7 \mathrm{~m} \mathrm{Ma}^{-1}$ 和 $500 \mathrm{~m}$ ); 晚中新世以来快速抬 升期(约 $15 \mathrm{Ma}$ )平均抬升速率和平均隆升幅度分别达 $125 \mathrm{~m} \mathrm{Ma}^{-1}$ 和 $1560 \mathrm{~m}$.

印支晚期以来 ${ }^{[12,13]}$ 若尔盖盆地开始褶皱造山发 生隆升剥蚀作用, 其晚中生代、新生代隆升幅度不低
于 $3400 \mathrm{~m}$, 结合热年代学特征与区域地质特征可知 川西高原的形成过程主要发生于中新世以来 ${ }^{[14,15]}$, 而区内的差异隆升直接决定着裂缝系统及断层的活 动性, 必将强烈地影响若尔盖地区流体(油气)的运移 和聚集.

\section{2 隆升过程古流体响应活动证据}

\section{1 脉体产状特征}

流体运移发生于不同尺度的裂隙系统中，而大 部分裂隙和脉簇呈集中分布, 多数具对数正态分布 特征, 所以脉体的空间分布特征是评价流体流动的 一个重要标志. 基于野外露头裂缝及脉体空间分布 几何形态、贯通性质和运动学等特征研究, 若尔盖地 区脉体主要有三类: 第一类是成岩期脉体, 多为细网 状，常见于灰岩地层中; 第二类为成岩-变形期脉体, 楔形状, 多见追踪形态, 脉体高角度斜交(或垂直)于 地层层面(图 3(a)), 普遍分布于砂岩和灰岩地层, 尤 其是砂泥岩互层或灰泥岩互层中，脉体大多局限分 布于能干岩层中; 第三类是构造变形期脉体, 形态各 异, 呈顺层或切层发育, 集中分布于断裂构造破碎 带.

平面分布上，我们分别对若尔盖中北部三个地 区(热当坝垭口扎尔山组、唐克垭口北和唐克垭口南) 进行系统研究. 该地区地表脉体(含非充填脉体)宽度 大小呈分异特征，构造充填脉体具有较大的、非线形 的开放空间，表明裂缝系统具有较大的流体压力，岩 层应变破裂, 流体涌入沉淀, 形成形态各异的脉体.

垂向深度上, HC-1 井岩芯构造脉体形态与地表 特征对比变化较大．地表及浅部主要为垂直或高角 



图 2 若尔盖盆地 $\mathrm{AFT}$ 热隆升史反演及隆升速率综合图

(a) 若尔盖 AFT 反演隆升速率-时间曲线; (b), (c) 典型 AFT 样品热史模拟图
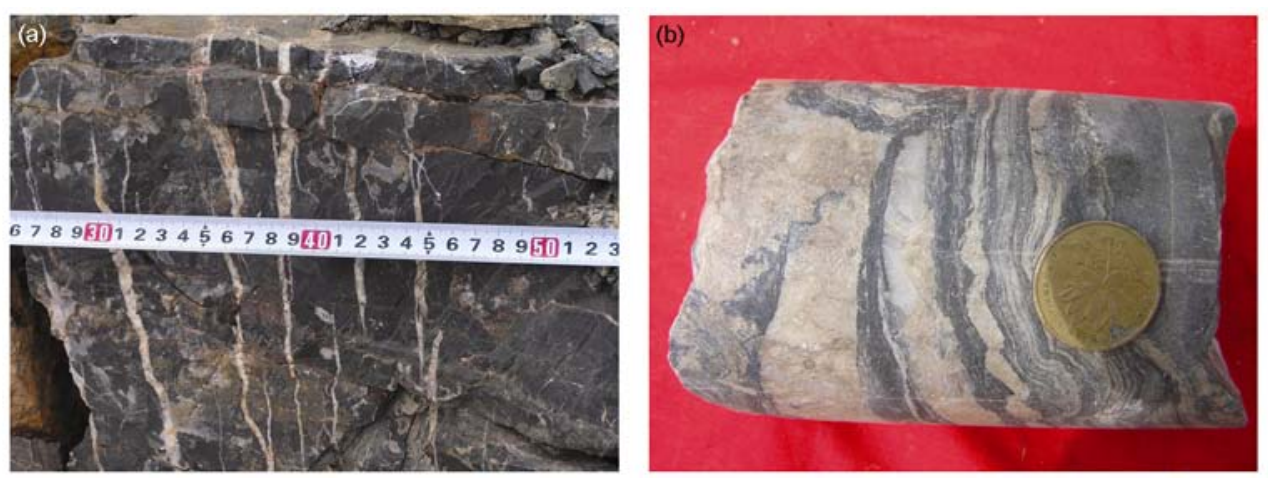

图 3 若尔盖地区地层含脉裂缝发育图

(a) 花湖杂尔山组垂直层面方解石脉体; (b) HC-1 井 $6071.30 \mathrm{~m}$ 顺层分布脉体

度斜交层理性裂缝(图 3(a)), 多切穿岩层, 脉体具压张性裂隙充填特征, 脉体发育于砂岩地层中-高角度 裂隙系统; 岩芯深部(尤其是 $6000 \mathrm{~m}$ 以下), 脉体(石 英和方解石充填)数量和宽度显著增多, 主要为层内 脉体(图 3(b)), 壁较平直, 多沿平行层面性裂隙(产状 平缓)充填, 脉体以压-剪性裂隙充填特征为主.

\section{2 脉体地球化学特征}

通过对若尔盖-唐克地区地表三叠系中具构造流 体活动性质的第二和三类高角度脉(或垂直层面脉体) 和断裂破碎带附近脉采样, 以及对 HC-1 井取芯段裂 隙脉体系统取样, 包裹体以微裂隙包裹体为主, 少量 分布于自生石英和方解石胶结物, 均一温度变化较 大(图 4), 为 $91 \sim 430^{\circ} \mathrm{C}$, 其中方解石和石英均一温度 分布特征具有明显差异. 方解石脉体中流体包裹体
均一温度值明显偏低, 温度集中分布于 131 170 和 240 $260^{\circ} \mathrm{C}$ 区间，且若尔盖-唐克地区的东、北和西部， 均一温度值相对要低; 石英脉体中包裹体均一温度 明显偏高, 较集中分布于 $191 \sim 291^{\circ} \mathrm{C}$ 区间. 本区流体 至少经历过两次构造热流体活动, 形成方解石脉体 和石英脉体包裹体均一温度分异特征.

流体包裹体静水压力系数比体现了包裹体捕获 时古压力值与现今静水压力之比, 而恢复地层隆升 剥蚀前古压力系数为包裹体捕获压力与隆升前包体 原位静水压力之比, 它们真实反映出流体不同阶段 的压力状态. 根据岩层应力-应变机制, 当地层中孔 隙流体异常压力较 (很) 高, 达到上覆静岩压力的 0.7 0.9 倍时(相当于静水压力的 1.6 2.0 倍, 据李明 诚 ${ }^{[20]}$ ), 岩层易产生张性微裂缝, 释放流体(异常)高 压而排泄流体, 由此可知, 在现今正常静水压力梯度 


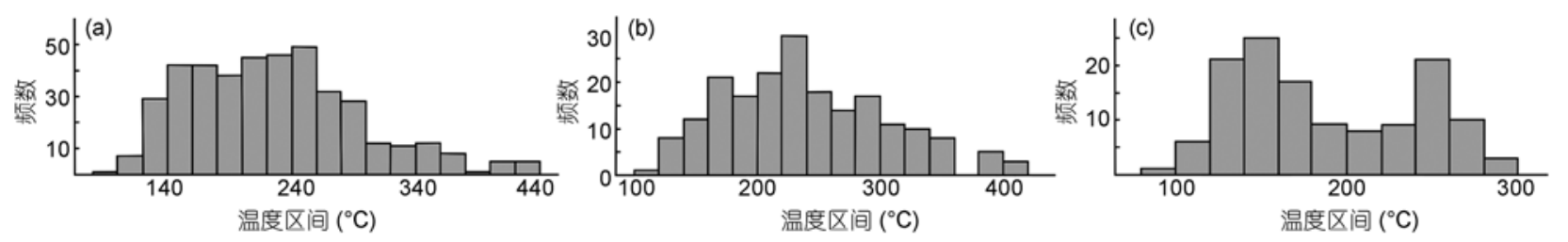

图 4 若尔盖地区三叠系包裹体均一温度

(a) 包裹体均一温度直方图; (b) 石英包裹体均一温度直方图; (c) 方解石包裹体均一温度直方图

下，流体包裹体(或流体囊)难以捕获和保存高压力系 数比(压力系数比>1.6) 的流体体系. 根据对若尔盖地 区少量地表和 HC-1 井(主要)垂向脉体系统采样, 在 西安地质矿产研究所实验测试中心对脉体包体进行 成分激光拉曼探针(RAMANOR-U1000, SX-02)分析, 以及均一温度和冷冻冰点等分析测定 (表 2), 获得流 体包裹体盐度和均一温度. 进一步通过经验公式(据 郡洁涟和梅建明 ${ }^{[21]}$ 、刘斌和沈昆 $\left.{ }^{[22]}\right) P=P^{0} \times t_{1} / t_{0}$, 式中: $P^{0}=(219+2620 N) \times 1.01325 \times 10^{5} ; t_{0}=374+920 N ; P$ 为捕 获压力 $(\mathrm{Pa}) ; t_{1}$ 为捕获温度即均一温度 $\left({ }^{\circ} \mathrm{C}\right) ; t_{0}$ 为初始 温度 $\left({ }^{\circ} \mathrm{C}\right) ; N$ 为盐度 $(\mathrm{wt} \%)$.

逐步计算得到流体捕获压力 $P$, 通过系统检验计 算结果符合常理且基本满足本区地质特征, 具有较 高可信度, 随后通过捕获压力与包裹体现今深度地 层压力相比得到现今压力系数比. 伴随阶段性隆升 过程, 流体脉体垂向空间分布位置也发生相应变化, 通过恢复地层不同隆升阶段实际剥蚀幅度计算出早 期流体原位原始地层压力, 进而与包裹体捕获压力 相比得到古压力系数比(表 2). 基于此, 根据流体包 裹体现今压力系数和恢复隆升前(原位)古压力系数, 可以区分出三期不同构造抬升阶段的流体包裹体.

第一类包裹体高现今压力系数 $(>1.6)$, 高古压力 系数 $(>1.6)$; 第二类包裹体高现今压力系数 $(>1.6)$, 中 低值古压力系数 $(<1.6)$; 第三类中低现今压力系数 $(<1.6)$, 低古压力系数 $(<1)$, 它们分别对应于早期高 压流体包裹体(隆升期前流体捕获包裹体, 后期压力 梯度环境下难以捕获该异常高压包裹体体系)、中期 中高压流体包裹体(隆升期流体捕获包裹体)和晚期 常压流体包裹体.

根据不同阶段构造脉体盐度-温度协变图研究, 若尔盖地区流体盐度-温度(图 5)在构造抬升过程中 发生了显著的变化, 早期(隆升前阶段)包裹体盐度集 中在 $15 \%$ 附近, 而温度变化范围较大, 反映出受深部 热流影响下的增温效应; 而隆升中、后期中-高压包裹 体以及晚期常压包裹体, 温度和盐度变化范围较大,
二者呈近似的线性关系，反映出与淡水流体混合的 演化趋势, 它反映了隆升过程中深和浅部流体混溶 的过程.

从三叠系地表和岩芯构造裂隙中脉体碳氧同位 素平面空间特征来看, 若尔盖腹部地区构造裂隙充 填物 $\delta^{13} \mathrm{C}$ 和 $\delta^{18} \mathrm{O}$ 值较低(图 6), $\delta^{13} \mathrm{C}_{\mathrm{PDB}}$ : $-11.7 \%$ 4.4\%o, $\delta^{18} \mathrm{O}_{\mathrm{PDB}}:-26.8 \%$ - 5.6\% , 呈南北走向展布, 而其东、 北和西部 $\delta^{13} \mathrm{C}$ 和 $\delta^{18} \mathrm{O}$ 值大, $\delta^{13} \mathrm{C}_{\mathrm{PDB}} \geqslant 0, \delta^{18} \mathrm{O}_{\mathrm{PDB}} \leqslant$ $-14 \%$. 若尔盖腹部地区流体系统为受下渗大气水影 响的开放性体系, 断裂带流体来源以大气淡水为主. 开放性流体动力环境是早期热流体增温与中后期大 气淡水下渗作用的多期流体活动混染综合的结果, 而垂向空间上的高角度裂缝系统为浅和深部流体彼 此混染形成开放性流体动力环境, 可能提供了空间 上流体连通的基本物质条件.

\section{3 脉体形成时期}

宏观上，从脉体充填成分来看，中三叠、上三叠 统脉体主要充填成分具有一定的差异性, 上三叠统 (新都桥组、侏倭组和杂谷脑组)多见石英充填脉体, 中三叠统 (扎尔山组)岩层以石英-方解石混合充填, 但普遍以方解石脉体为主. 宏观和微观上脉体充填 都具有多期性特征, 岩层中方解石和石英脉体彼此 穿切关系明显，同一构造脉体中，多见后期方解石脉 体切割早期石英脉. 进一步结合石英和方解石包裹 体均一温度分布特征可知(图 4), 石英和方解石充填 序列与均一温度具正相关性, 即石英脉体充填较早, 具有温度分布区间大, 峰值温度高的特点, 而方解石 后期充填, 峰值温度则相对较低.

热流体是构造活动中最活跃的因素，与构造运 动相伴的脉体和岩浆则是流体物质循环过程的直接 记录和良好标志. 电子顺磁共振测年(ESR)是一种根 据样品所吸收的自然辐照剂量来推导样品形成年代 的测年方法 ${ }^{[22,23]}$, 通过构造脉体矿物(石英)热活化 ESR 测年，可以大致确定构造脉体中生代、新生代以 
表 2 若尔盖地区流体包裹体气相特征及压力分类 ${ }^{a)}$

\begin{tabular}{|c|c|c|c|c|c|c|c|c|c|c|}
\hline 样号 & $\mathrm{CO}_{2}$ & $\mathrm{CH}_{4}$ & $\mathrm{C}_{2} \mathrm{H}_{6}$ & $\mathrm{H}_{2} \mathrm{O}$ & 盐度 $(\mathrm{wt} \%)$ & $T_{\mathrm{h}}\left({ }^{\circ} \mathrm{C}\right)$ & $P(\mathrm{MPa})$ & 现今压力系数 & 古压力系数 & 分期 \\
\hline $\mathrm{Hj}-25$ & 78.7 & 3.4 & 2.1 & & 13.1 & 264.9 & 74.6 & 7.2 & 2.2 & 1 \\
\hline $\mathrm{Hj}-5$ & 38.6 & & & 27.8 & 12.0 & 183.3 & 55.4 & 10.5 & 1.6 & 1 \\
\hline $\mathrm{Hj}-22$ & 29.9 & 6.2 & & & 12.6 & 183.9 & 51.7 & 11.6 & 1.8 & 1 \\
\hline R018 & 38.3 & & & & 8.41 & 224.6 & 62.4 & & 1.8 & 1 \\
\hline R50 & 56.2 & 11.1 & & & 10.94 & 217.1 & 60.8 & & 1.8 & 1 \\
\hline R57 & 69.2 & 9.7 & & & 20.63 & 214.9 & 60.8 & & 1.8 & 1 \\
\hline $\mathrm{Hj}-26$ & 40.1 & & 1.6 & & 7.0 & 150.7 & 41.6 & 3.2 & 0.9 & 2 \\
\hline $\mathrm{Hj}-35$ & 62.0 & 16.4 & & & 12.3 & 220.0 & 61.9 & 1.6 & 0.9 & 2 \\
\hline $\mathrm{Hj}-10$ & 56.6 & & 9.1 & & 17.06 & 267.2 & 75.79 & 1.9 & 1.0 & 2 \\
\hline $\mathrm{Hj}-3 \mathrm{c}$ & 48.3 & 12.4 & & 38.2 & 8.74 & 168.2 & 46.82 & 2.4 & 0.9 & 2 \\
\hline $\mathrm{Hj} 29 \mathrm{c}$ & 25.6 & 8.9 & 7.3 & & 6.9 & 176.1 & 48.6 & 1.6 & 0.8 & 2 \\
\hline $\mathrm{Hj} 33 \mathrm{c} 1$ & 27.7 & 8.1 & 4.1 & & 13.8 & 219.0 & 61.8 & 1.6 & 0.9 & 2 \\
\hline $\mathrm{Hj} 33 \mathrm{c} 2$ & 32.5 & 6.7 & & & 14.4 & 213.8 & 60.3 & 1.6 & 0.9 & 2 \\
\hline $\mathrm{Hj}-32$ & 8.5 & 8.5 & 5.0 & & 3.2 & 209.8 & 55.1 & 1.5 & 0.8 & 3 \\
\hline $\mathrm{Hj} 11 \mathrm{c}$ & 64.0 & 9.1 & & & 19.68 & 193.6 & 54.97 & 1.4 & 0.7 & 3 \\
\hline $\mathrm{Hj}-7 \mathrm{c}$ & 84.9 & 9.5 & & & 6.08 & 161.9 & 44.40 & 1.2 & 0.6 & 3 \\
\hline $\mathrm{Hj}-36$ & 71.2 & 9.7 & 6.6 & & 6.8 & 176.1 & 48.4 & 1.2 & 0.6 & 3 \\
\hline $\mathrm{Hj}-33$ & 5.4 & 7.9 & 1.4 & & 5.1 & 147.9 & 40.2 & 1.1 & 0.6 & 3 \\
\hline $\mathrm{Hj} 41(2)$ & 25.5 & 1.8 & & & 8.3 & 206.2 & 57.3 & 0.9 & 0.6 & 3 \\
\hline $\mathrm{Hj}-13$ & 51.9 & 5.5 & & & 14.98 & 188.5 & 53.25 & 1.1 & 0.6 & 3 \\
\hline $\mathrm{Hj} 46(2)$ & 58.4 & 5.8 & & & 11.1 & 181.7 & 51.0 & 0.8 & 0.6 & 3 \\
\hline $\mathrm{Hj}-39$ & 68.2 & 11.5 & & & 13.1 & 232.2 & 65.4 & 1.1 & 0.7 & 3 \\
\hline
\end{tabular}

a) 1. 早期高压包裹体, 2. 中期中-高压包裹体, 3. 晚期常压包裹体; $T_{\mathrm{h}}$ 为均一温度, $P$ 为包裹体捕获压力值; 所有样品由西安地质矿产研 究所测试

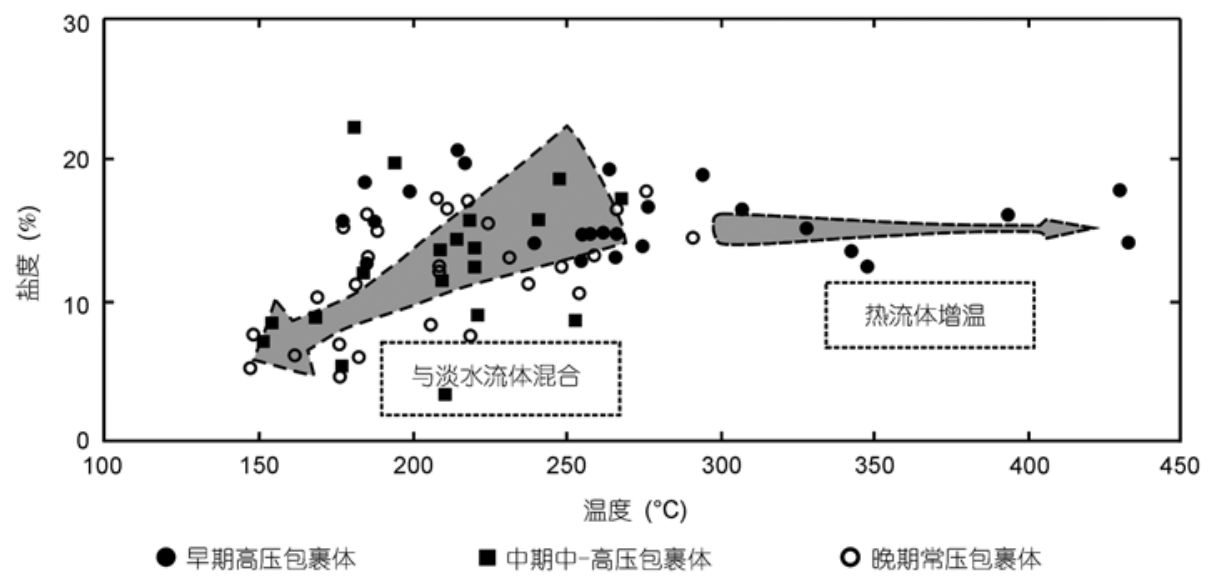

图 5 若尔盖及周边地层中构造流体包裹体盐度与温度关系变化

来的活动时间和期次 ${ }^{[24,25]}$, 尤其是对新鲜样品的新 生代年龄测定具有较高的可信度, 近年来引起地质 学家的广泛关注和采用. 在若尔盖地区系统采集了 中三叠、上三叠统地层脆性构造变形中伴生的新鲜石 英脉样品 40 余件 (另见详文), 自然风干、碎样后在 成都理工大学应用核技术研究所进行了单矿物石英 样品 ESR 测年, 石英年龄值分布范围较广 (图 7(a)),
为 $(2.0 \pm 0.3) \sim(208.3 \pm 20.0) \mathrm{Ma}$, 主要集中于燕山期和 喜马拉雅期, 尤其是中新世以来( 30 Ma)石英样品测 年值显著集中, 反映了流体活动的多期性, 且石英测 年值集中分布特征与区域晚白严世以来阶段性快速 隆升在时间上具有一定的对应关系, 阶段性的快速 抬升过程与流体活动的多期性可能具有深层次的成 因联系. 进一步通过对若尔盖地区岩体同位素年代 

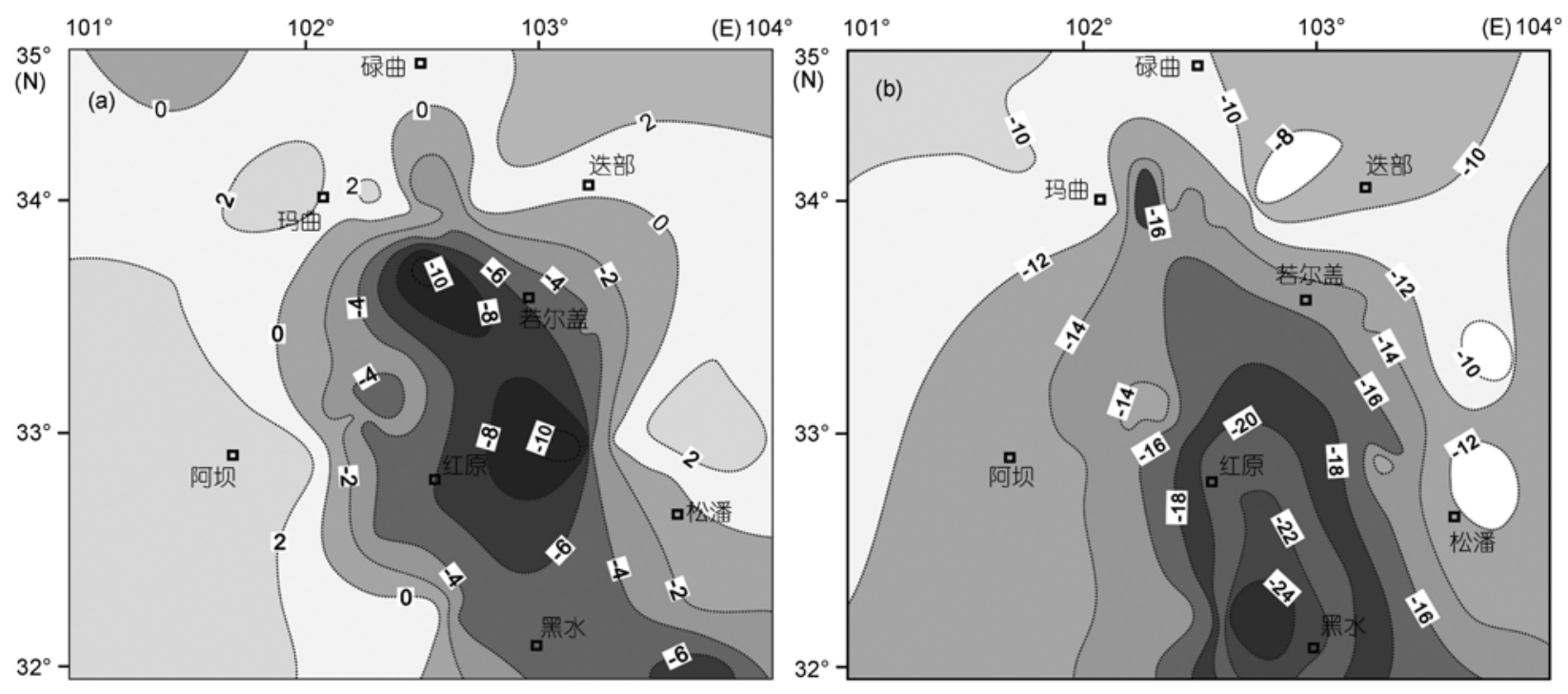

图 6 若尔盖地区地表三叠系构造脉体 $\delta^{13} \mathrm{C}_{\mathrm{PDB}}(\mathrm{a})$ 和 $\delta^{18} \mathrm{O}_{\mathrm{PDB}}(\mathrm{b})$ 平面分布(据楼章华 ${ }^{1)}$ 修改)
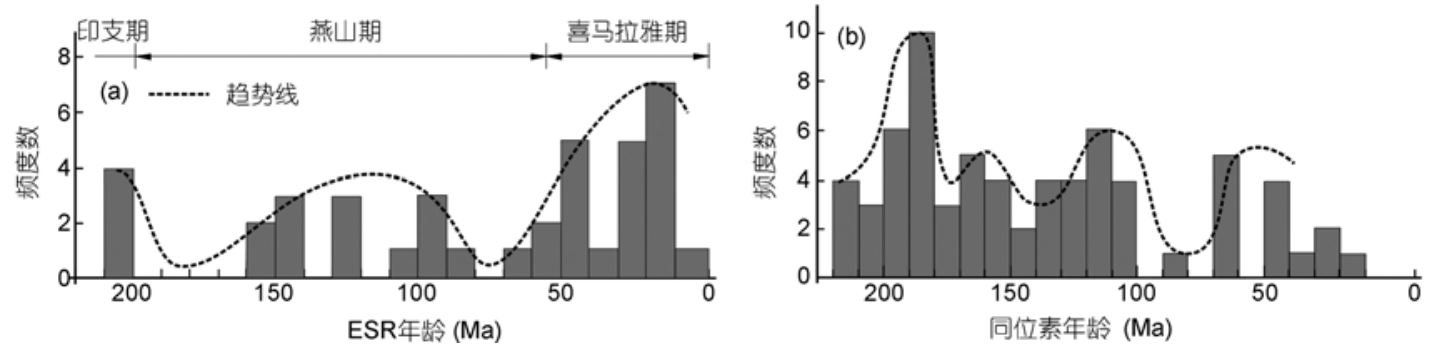

图 7 若尔盖地区三叠系构造脉体年龄统计直方图

(a) 石英测年 ESR 统计图; (b) 同位素测年统计图

学统计表明, 中新生代以来若尔盖地区岩浆热流体 活动活跃(图 7(b)), 具明显多期性, 同时三叠系构造 带石英脉体多期形成时代与周边构造-成矿多期活动 年龄 ${ }^{[26]}$ 具有较大的相似性. 总体而言, 构造流体活动 的多期性与周缘地区 (尤其是西秦岭南亚带)多期成 矿特征具有一定的参照性, 构造流体活动比区域断 裂强烈活动期相对较晚一些.

\section{3 隆升作用与流体活动耦合效应}

\section{1 隆升作用过程中流体应力场变化机制}

岩层隆升与沉降过程应力机制具有显著的差异, 沉降过程中岩层变形多遵循“pseudo-elastic”应变机 制, 而隆升过程中岩层大体遵循线性应力-应变机
制 $^{[27,28]}$, 尤其是持续埋深沉降和隆升导致的温差效 应将对岩层弹性模量和泊松比产生显著影响. 抬升 剥蚀地区, Brown-Hoek 应力模式(BHSP)普遍存在于 地表浅层 ${ }^{[29 ~ 31]}$, 伴随深度变浅最小水平主应力与垂 直主应力比值 $\left(R=S_{\mathrm{hmin}} / S_{\mathrm{v}}\right)$ 逐渐增大 (图 8 ), 即使是在 结晶基底地区, 张性正断区域 ${ }^{[31]}$, 致使浅层最小与最 大主应力 $S_{\mathrm{hmin}}$ 与 $S_{\mathrm{v}}$ 发生显著变化调整. 当最大、最 小和垂直应力的关系为 $S_{\mathrm{H}}>S_{\mathrm{h}}>S_{\mathrm{v}}, S_{\mathrm{H}}>S_{\mathrm{v}}>S_{\mathrm{h}}$ 和 $S_{\mathrm{v}}>S_{\mathrm{H}}>S_{\mathrm{h}}$ 时 $\left(S_{\mathrm{H}}\right.$ 和 $S_{\mathrm{h}}$ 分别为水平最大和最小主应力, $S_{\mathrm{v}}$ 为垂向主压力), 分别有利于逆断层、走滑断层和正断 层活动. 因此伴随隆升剥露过程, 地层垂向深度的动 态变化必将导致岩层应力环境变化, 发生一系列具 不同岩石破裂行为特征的构造运动.

一般而言, 均衡隆升过程中存在两种端元的应

1) 楼章华. 松潘-阿坝地区油气保存条件研究报告. 中石化南方公司. 2003 


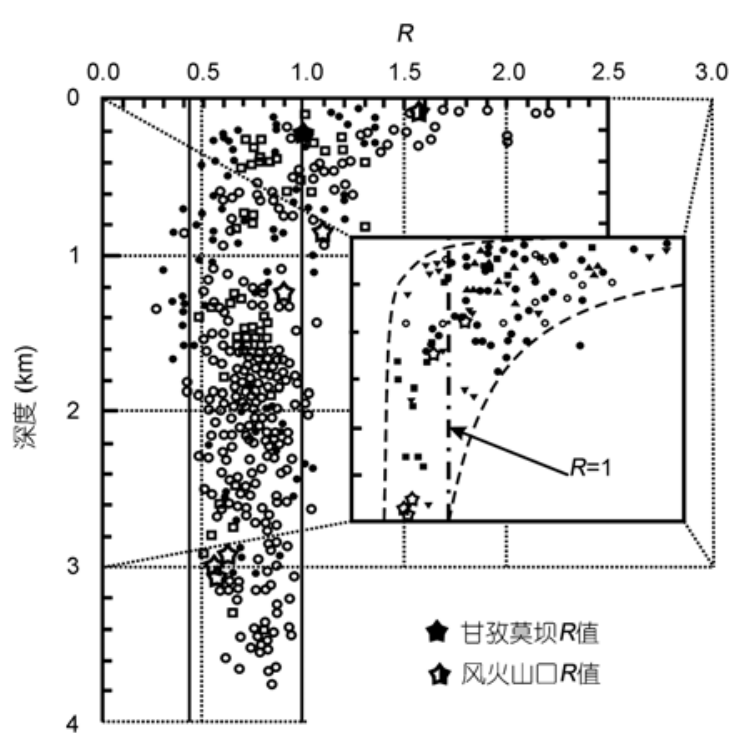

图 8 Brown-Hoek (BHSP)应力模式

据文献[31]修改. 青藏高原东缘甘孜莫坝和风火山口砂岩水平最小 主应力值分别据王学潮等 ${ }^{[32]}$ 和吴满路等 ${ }^{[33]}$; 不同岩性符号: 砂岩, 未充填圆圈; 页岩, 充填圆圈; 碳酸盐岩, 正方形; 右方插入小图为 Brown 和 Hoek ${ }^{[29]}$ 各岩性(结晶岩和沉积岩)BHSP 图, 数据采集地分 类: 斯堪的纳维亚, 未充填圆圈; 澳大利亚, 充填圆圈; 加拿大, 上 三角形; 美国, 倒三角形; 南非, 正方形; 德国深部钻井, 星形

力变化机制: 平行隆升与非平行隆升机制. 平行隆升 过程中(图 9(a)), 岩层处于均匀水平应力场作用, 水 平最小主应力小于垂向应力(静岩压力), 两者大小关 系主要由地层静水压力与静岩压力比值和内摩擦角 决定. 软弱岩层内摩擦角低, 水平应力与垂直应力比 值较大 $(>1)$; 而能干层内摩擦角较大, 水平应力与垂 直应力比值较小 $(<1)$; 尤其是含超压流体系统能大大 改善应力条件, 增大水平应力. 根据地表浅层
Brown-Hoek 应力模式伴随区域隆升过程最小与最大 主应力 $S_{\mathrm{hmin}}$ 与 $S_{\mathrm{v}}$ 发生变化调整, 软弱岩层的水平应 力易于近地表 (约 $1.2 \mathrm{~km}$ ) 处超过垂向静岩压力 $\left(S_{\mathrm{H}}>S_{\mathrm{h}}>S_{\mathrm{v}}\right)$, 而形成走滑逆冲破裂; 相反能干岩层中 水平应力伴随隆升将会逐渐减小而低于静水压力 $\left(S_{\mathrm{H}}>S_{\mathrm{v}}>S_{\mathrm{h}}\right)$, 在近地表处水力破裂临界点(约 $2.7 \mathrm{~km}$ ) 发生张性走滑破裂(高角度斜交于层理裂缝).

非平行隆升过程中(图 9(b)), 岩层处于差异水平 应力场作用下 (盆地长轴方向处于张性应力, 盆地短 轴方向处于压性应力), 最小水平应力 ( $S_{\mathrm{h}}$, 平行于盆 地长轴方向)伴随隆升逐步降低, 而在地表约 $2 \mathrm{~km}$ 水 力破裂临界点变为小于静水压力 $\left(S_{\mathrm{H}}>S_{\mathrm{v}}>S_{\mathrm{h}}\right)$, 因此易 于发生走滑破裂，尤其是在岩层浅部其差值达到地 层抗张强度 $(T)$ 时, 发生水力破裂, 形成裂缝系统; 水 平最大应力 $\left(S_{\mathrm{H}}\right)$ 伴随隆升过程应力值逐渐增大, 约 4 $\mathrm{km}$ 应力转换临界点处超过垂向静岩压力 $\left(S_{\mathrm{H}}>S_{\mathrm{v}}>S_{\mathrm{h}}\right)$, 因此岩层处于应力转换临界位以上深度时, 更倾向 于产生走滑破裂, 形成高角度斜交于层理的裂缝.

青藏高原震源机制解和地质构造资料显示，青 藏高原东缘地区应变场以近 NE-EW 向的主压应变为 主体, 同时伴随着近 NW-SN 向的张性应变 ${ }^{[32 ~ 35]}$, 表 明其最大和最小水平应力分别为应变最大和最小主 应力, 符合 Brown-Hoek 浅层应力模式(图 8). 伴随隆 升过程中最小主应力与中间主应力的动态调整变化 $\left(S_{\mathrm{h}}\right.$ 与 $\left.S_{\mathrm{v}}\right)$, 浅层地表处不同地区具有不同特征(尤其 是具有异常流体高压和软弱岩层滑脱变形地区), 其 水平最小应力与垂向主应力大小比值决定了不同构 造破裂变形行为特征, 在甘孜莫坝地区 $R \approx 1$, 风火山 口 $R \approx 1.5$ (图 8), 岩层分别有利于发生走滑破裂和逆冲
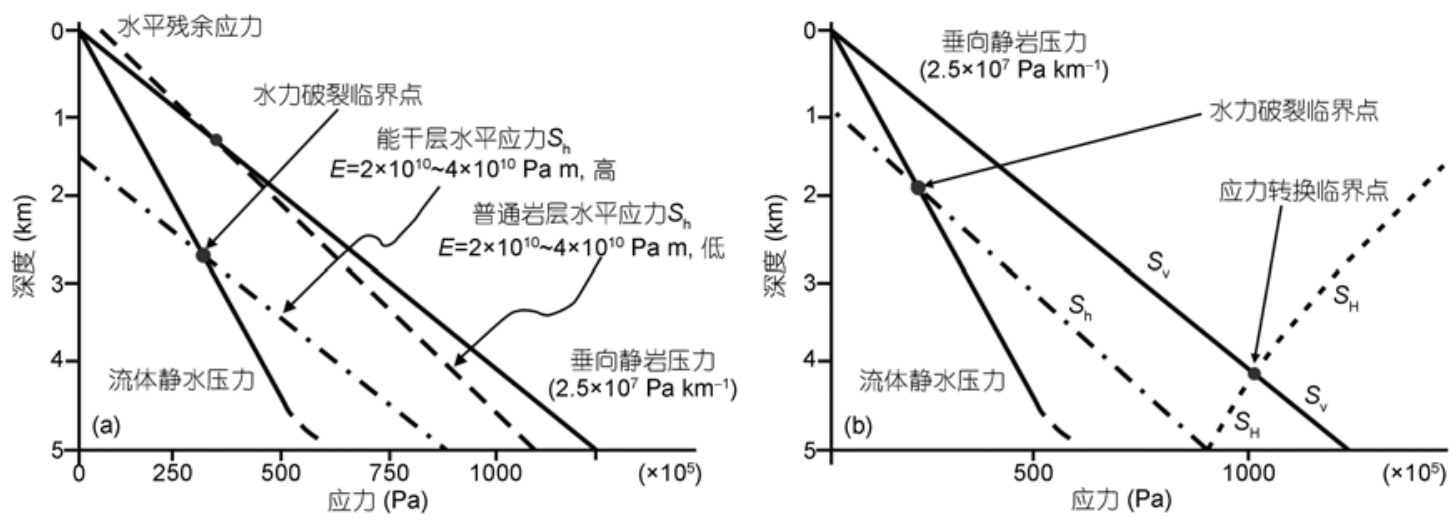

图 9 均衡隆升过程应力变化曲线

(a) 平行隆升模式; (b) 非平行隆升模式. 据 Price 和 Cosgrove $e^{[27]}$ 修改 
构造, 尤其是当处于非平行隆升端元模式, 将发生以 走滑破裂为主的构造变形, 形成高角度的裂缝系统. 岩石破裂缝走向主要受水平应力 $\left(\sigma_{1}\right.$ 和 $\left.\sigma_{2}\right)$ 控制, 主应 力强度存在显著差异时, 走向与 $\sigma_{2}$ 近平行, 相反其走 向则呈随机分布 ${ }^{[30]}$. 在盆-山系统中, 水平挤压应力 $\left(\sigma_{1}\right)$ 在平面空间和垂向深度上普遍具有逐步减弱的趋 势, 沿造山带向盆地方向差值应力逐渐减小, 因而导 致裂缝走向的变化. 造山带附近裂缝走向以平行造 山带为主, 远离造山带裂缝走向则以垂直造山带为 主 ${ }^{[36]}$, 这与若尔盖地区 $\delta^{13} \mathrm{C}_{\mathrm{PDB}}$ 和 $\delta^{18} \mathrm{O}_{\mathrm{PDB}}$ 等值线呈南 北走向展布特征(流体活动趋势方向)具有一定印证. 总体而言, 若尔盖地区浅部应力场和高角度裂缝系 统特征与均衡隆升过程中非平衡隆升模式应力场和 裂缝系统特征具有一定的相似性.

瞬时(非稳态)流体流动过程中构造应力(构造活 动)变化为岩石应变的关键控制因素, 导致地层破裂 或先存裂隙、断层再次(或多次)开启, 引发发生(穿层) 流体运移. 盆地应力状态在不同时期、不同构造阶段 存在着巨大差异, 且某一深度的差异应力不仅受控 于构造应力场, 而且与地层密度、杨氏模量、泊松数 和热膨胀系数等多种因素密切相关. 理想均衡隆升 端元模型未曾考虑构造挤压体制下隆升过程中瞬时 应力释放机制, 尤其是快速隆升过程引起的流体系 统围限压力的改变 (甚至超过静岩压力, 压力系数比 $>1.6$, 流体压力系统趋于恢复平衡稳态, 必然诱发 岩石应变的快速响应(尤其是存在超压流体系统时), 产生大量裂缝释压和流体排泄活动, 因而野外实际 裂缝系统发育特征较理想端元模型(平行隆升和非平 行隆升端元模型)特征更复杂多样.

\section{2 阶段性隆升作用与流体幕式流动模式}

构造隆升引起的地层能量效应较为复杂, 一方 面, 抬升剥蚀可导致剥蚀反弹, 在封闭层之下出现负 压以及地层压力低于相应静水压力, 形成泵吸效 应 $^{[37]}$; 另一方面, 抬升剥蚀可在一定条件下导致地 层破裂压力降低(图 10), 发生流体破裂, 它们都会强 烈影响盆地温、压场态 ${ }^{[30,38]}$. 一般而言, 隆升导致最 直观的效果即为地层温度和压力的变化, 按静水压 力和若尔盖地区地温梯度计算, 隆升 $1300 \mathrm{~m}$, 地层 围压会减小 $12.7 \mathrm{MPa}(P=\rho g h$, 地层水密度 $\rho$ 取 $1 \mathrm{~kg}$ $\left.\mathrm{m}^{-3}, g=9.8 \mathrm{~N} \mathrm{~kg}^{-1}, h=3000 \mathrm{~m}\right)$, 地温降低 $42^{\circ} \mathrm{C}$; 而隆
升 $3400 \mathrm{~m}$, 地层围压将会减小 $33.3 \mathrm{MPa}$, 地温降低 $110^{\circ} \mathrm{C}$. 由此看出, 动态隆升过程中被包裹体捕获和 赋存的早期主体流体系统(或流体囊)相对于(隆升后 非原位)围岩温度或压力比值将会显著变化(表 2).

静态上, 若尔盖地区 HC-1 井流体包裹体压力大 小垂向特征相似, 包裹体压力分布于 41 78 MPa 范 围, 主要集中于 $50 \sim 70 \mathrm{MPa}$ (图 10). 中、深部 (3000 7000 m) 普遍位于现今静水压力梯度曲线和静 岩压力梯度曲线之间, 深部有局部点位于现今静水 压力梯度曲线下方，表明深部存在一定的欠压实; 而 浅部包裹体压力总体位于现今静岩压力曲线上方, 仅局部位于现今静水压力梯度曲线和静岩压力梯度 曲线之间, 表明主体应为抬升剥蚀前包裹体捕获的 早期主体流体系统(或流体囊), 否则现今压力梯度场 态下难以达到压力稳态赋存.

动态上结合阶段性隆升过程来看, 早期晚白严 世隆升前期深部地区主体流体系统压力(等于同期包 裹体压力梯度) 完全位于同期静岩压力梯度(隆升 $3400 \mathrm{~m}$ 前静岩压力梯度)曲线下方(图 10), 流体压力 未能突破破裂压力梯度曲线产生破裂, 难以发生大 量流体涌流活动, 流体主要受深部热流影响, 因而包 裹体温度-盐度特征以热流体增温变化为主(图 5). 在 地表浅部, 根据均衡隆升过程和 Brown-Hoek 应力模 式, 伴随隆升过程中最小主应力与中间主应力的变 化, 浅层地表处不同地区具有不同特征, 岩层发生逆 冲或走滑破裂 $(R>1$ 或 $R \leqslant 1$ ), 形成一系列裂缝系统, 有利于地表大气淡水下渗, 深浅部流体混溶, 这与若 尔盖地区现今地表淡水流体混合特征的 $\delta^{13} \mathrm{C}_{\mathrm{PDB}}$ 和 $\delta^{18} \mathrm{O}_{\mathrm{PDB}}$ 值(图 6)和中后期包裹体温度-盐度特征相符.

晚白严世发生快速阶段性隆升过程导致地层应 力场改变, 围岩静岩压力降低, 增大主流体系统相对 压力比(包裹体捕获压力/抬升后异位围岩压力比值 $>1.6$ ), 导致岩体高角度张-剪性破裂释放流体压力(可 能为相对高压), 发生流体涌流(图 10 中早期破裂圆), 流体沿浅部破裂缝系统与地表下渗大气淡水发生混 流. 而相对压力系数未能超过同期静岩压力梯度的 主流体系统可能未能产生破裂, 发生涌流(图 9 中现 今静岩压力梯度曲线和隆升 $1300 \mathrm{~m}$ 前静岩压力梯度 曲线之间所围限的主体流体系统). 流体囊破裂释压 后, 压力降低将会逐渐达到平衡状态, 裂缝系统封闭, 流体活动趋于平静. 这与前述构造脉体年龄测定及 其统计分布特征相符(图 7 中晚白严世后期的统计趋 


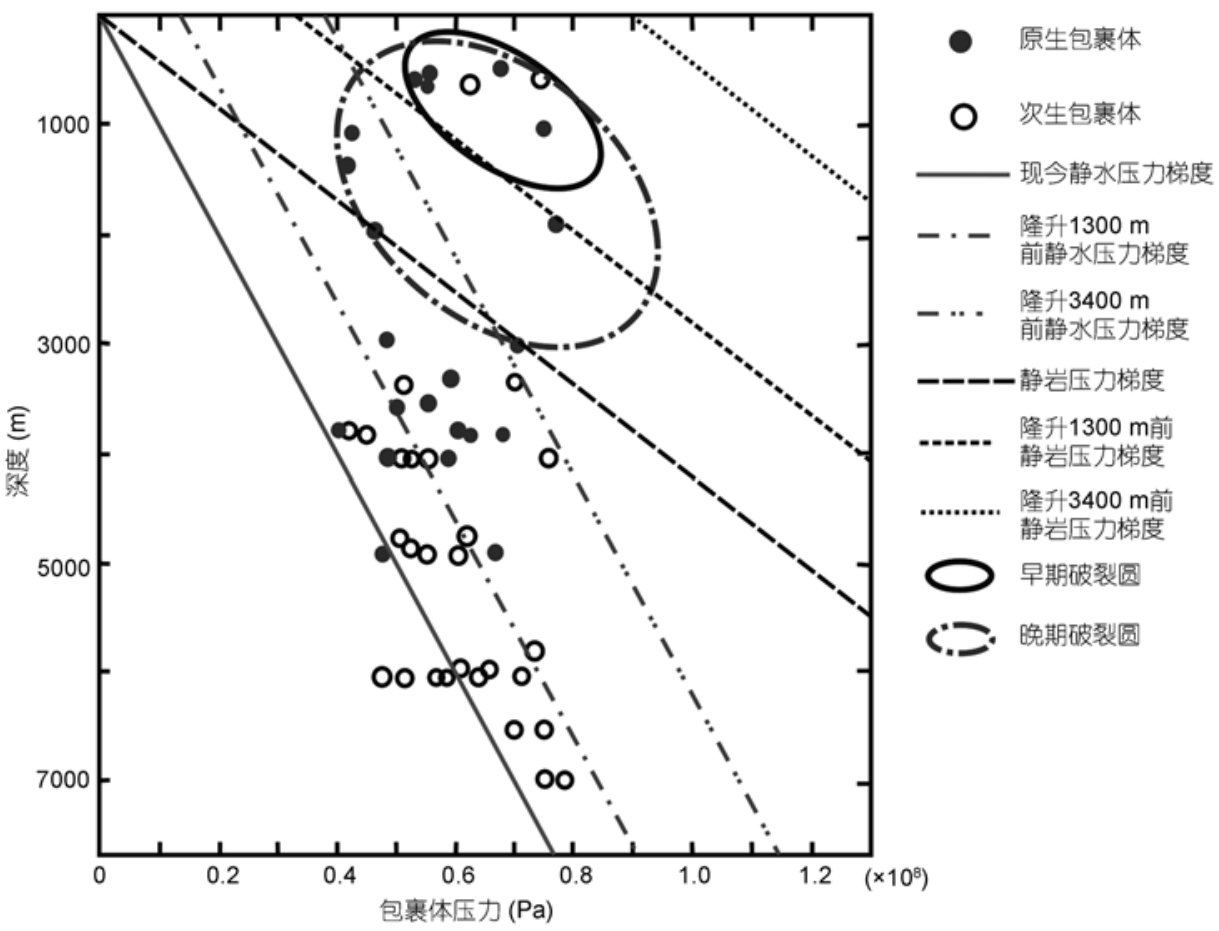

图 10 若尔盖地区 $\mathrm{HC}-1$ 井流体应力破裂综合演化图

势波谷区间)。

古近纪隆升剥蚀活动平静期(图 2), 地层抬升近 似处于均衡隆升状态, 应力场变化可能较小, 围岩静 岩压力未发生(或少发生)降低, 主流体系统相对压力 比变化微弱, 其累积产生压力梯度变化范围较小 (45 $\mathrm{Ma}$ 隆升 $500 \mathrm{~m}$, 地层围压会减小 $4.9 \mathrm{MPa}$ ), 难以形成 大规模的流体系统释压涌流, 此阶段更有利于流体 系统压力场态的平衡稳态恢复, 为后期抬升剥蚀岩 体破裂和大规模流体涌流埋下伏笔. 此时可能会伴 随压力的微量调整和积累, 流体系统局部相对压力 超过毛细管排替压力(尚未达到地层的破裂压力), 流 体会沿局部破裂向低应力场区域发生一定程度的渗 流，从而导致流体向前期断裂带汇聚.

阶段性稳压调整后, 新近纪以来区域进入高速 率、高幅度隆升阶段, 形成快速的流体释压过程 $(20$ $\mathrm{Ma}$ 隆升 $1700 \mathrm{~m}$, 地层围压会减小 $16.7 \mathrm{MPa}$, 温度降 低 $55^{\circ} \mathrm{C}$ ). 岩层应力场的改变必然诱发流体和围岩瞬 时压力调整, 产生裂缝, 而进一步持续的隆升作用使 早期主流体系统相对压力比超过同期静岩压力, 流 体囊流体发生岩层破裂流动, 流体因浅部高角度裂 缝系统的发育而进行跨层涌流活动(图 10 中晚期破裂 圆中主流体体系). 中晚期隆升过程中, 流体主要受
到以大气淡水下渗作用的浅部流体混染影响(图 6), 温度和盐度呈线性相关性减小(图 5).

从流体的地球化学特征来看，隆升前期脉体活 动主要受深部热流体影响, 温度-盐度特征以热流体 增温变化为主, 说明深部与浅部流体可能相互为独 立的流体体系; 而中后期隆升过程中，脉体温度-盐 度特征反映出与淡水流体混合趋势, 以大气淡水下 渗作用为主, 反映出深源和浅源流体混合形成开放 性流体动力环境, 表明流体活动经历明显的跨层运 移流动.

从流体的行为角度来看, 幕式流体流动的最重 要的特征是流体流动的不连续性、流体活动过程中的 温度和压力的快速变化以及流体活动的多期次性 ${ }^{[39]}$. 这些幕式流体流动特征在若尔盖地区的裂缝填充物 序列、包裹体温-压特征以及脉体活动年龄上都具有 相应表征, 快速隆升过程的压力(瞬时)变化调整为阶 段性岩层破裂和大规模流体释压涌流提供了基础条 件, 因此若尔盖地区与阶段性隆升过程相联系的多 期流体活动具有幕式特征. 流体幕式涌流是阶段性 快速隆升引起地层应力阶段性变化调整, 促使地层 破裂或断裂，先存裂隙再次开启，产生流体(释压)排 放的动态过程. 对于不同隆升剥蚀阶段流体活动强 
弱性特性而言, 单从脉体年龄统计直方图来看, 晚期 可能具有较强烈的流体活动, 但其具体行为特征仍 有待于研究.

\section{3 流体幕式流动产生的地质效应}

隆升作用引起岩层应力场改变, 主流体系统(流 体囊)压力超过静岩压力梯度, 导致流体-围岩有机体 系的压力调整, 因流体释压和围岩破裂而形成大规 模流体跨层涌流, 尤其是超压(欠压)系统对隆升过程 中裂缝发育分布和流体聚集运移更具有建设性 ${ }^{[3,40]}$ 的 影响作用.

地层深和浅部由于隆升过程中应力场的差异, 岩层发生不同的破裂行为, 因而裂缝系统的发育具 有不同的特征, 深部以低角度(或近水平)裂缝系统为 主, 不利于流体的跨层活动, 流体主要为顺层或层内 活动, 从而形成半原地“层内封闭”子系统, 有利于流 体 (油气) 保存; 浅部以高角度(或近垂直)裂缝系统为 主，为流体跨层流动提供了基本物质通道，同时为下 渗大气淡水和跨层流动的深部流体提供了混染空间, 形成浅层开放性流体动力环境. 发育低角度裂缝的 深部地层由于构造抬升作用隆升至地表浅部, 相应 导致其地层应力场转换而再次诱发形成高角度裂缝, 从而形成复杂的网状型裂缝系统, 在提高岩层裂缝 度的同时增大了流体跨层流动和相互混染的程度,
致使浅部流体系统具有对流驱动体制下的淡水流体 混合特征, 深浅部流体静态特征大致相似(图 10). 因 而, 若尔盖地区浅层流体开放性动力环境是阶段性 快速隆升过程促使流体释压、围岩破裂和流体跨层活 动过程多期叠加的综合结果.

\section{4 结论}

若尔盖地区晚白严世以来阶段性隆升幅度不少 于 $3400 \mathrm{~m}$, 晚白严世和晚中新世至今阶段式快速隆 升过程对本区流体应力场产生了重要影响. 本区浅 层流体为高角度 (或垂直)裂缝系统控制的开放性流 体体系, 具有早期热流体增温与中、晚期淡水流体混 合趋势下的多期流体混染特征, 流体幕式活动特征 明显, 多期活动与阶段性快速隆升过程具有对应性. 浅层流体开放性动力环境是阶段性快速隆升过程促 使围岩破裂, 流体释压跨层活动的动态结果, 高角度 裂缝系统为流体形成开放体系和跨层式流动提供了 基础条件.

“隆升释压”是阶段性隆升过程与流体活动时空 耦合的成因机制，同时也是流体运移和裂缝发育的 动力学成因, “幕式流动”是若尔盖地区流体运移的重 要方式, 是阶段性隆升过程与流体活动的时-空耦合 效应.

致谢 本文在研究过程中得到王成善教授和杨恒书高工的指导, 野外工作得到手波、孟伟、司建涛和胡爱平等的帮 助, 审稿专家提出宝贵意见, 在此谨表谢意.

\section{参考文献}

1 钟建华, 郭泽清, 杨树锋, 等. 柴达木盆地茫崖坳陷古近系-新近系 $R_{\mathrm{O}}$ 分布特征及地质意义. 地质学报, 2004, 78: 407-415

2 田丰华, 姜振学, 张晓波, 等. 地层抬升剥蚀对油气成藏贡献初探. 地质学报, 2007, 81: 273-279

3 刘树根, 李国蓉, 李巨初, 等. 川西前陆盆地流体的跨层流动和天然气爆发式成藏. 地质学报, 2005, 79: 690-699

4 刘树根, 孙玮, 李智武, 等. 四川盆地晚白严世以来的构造隆升作用与天然气成藏. 天然气地球科学, 2008, 19: 293-300

5 刘树根, 马永生, 孙玮, 等. 四川盆地威远气田和资阳含气区震旦系油气成藏差异性研究. 地质学报, 2008, 82: 328-337

6 王宗起, 汤耀庆. 大地构造学研究的新兴前沿课题——造山过程中的流体作用. 地学前缘, 1996, 3: 131-137

7 楼章华, 程军莣, 金爱民. 沉积盆地地下水动力场特征研究——以松辽盆地为例. 沉积学报, 2006, 24: 193-201

8 刘池洋, 张复新, 高飞. 沉积盆地成藏(矿)系统. 中国地质, 2007, 34: 355-374

9 Liu S G, Wang H, Sun W, et al. Energy field adjustment and hydrocarbon phase evolution in Sinian-Lower Palaeozoic Sichuan Basin. J China Univ Geosci, 2008, 19: 700-706

10 孙玮, 刘树根, 马永生, 等. 四川盆地威远-资阳地区震旦系油裂解气判定及成藏过程定量模拟. 地质学报, 2007, 81: 1153-1159

11 殷鸿福, 杨逢清, 黄其胜, 等. 秦岭及邻区三叠系. 北京: 中国地质大学出版社, 1992. 129-138

12 张国伟, 郭安林, 姚平安. 中国大陆构造中的西秦岭-松潘大陆构造结. 地学前缘, 2004, 11: 23-32

13 张风岭. 西秦岭南亚带构造演化模式讨论. 甘肃地质学报, 1993, 2: 72-79 
14 Enkelmann E, Ratschbacher L, Jonchheere R, et al. Cenozoic exhumation and deformation of northeastern Tibet and the Qinling: Is Tibetan lower crustal flow diverging around the Sichuan Basin. Geol Soc Am Bull, 2006, 6: 651-671

15 张克信, 王国灿, 陈奋宁, 等. 青藏高原古近纪-新近纪隆升与沉积盆地分布耦合. 地球科学, 2007, 32: 583-597

16 邓宾, 刘树根, 李智武, 等. 青藏高原东缘及四川盆地晚中生代以来隆升作用对比研究. 成都理工大学学报, 2008, 35: 477-486

17 邓宾, 刘树根, 李智武, 等. 青藏高原东缘地区隆升作用特征一一低温年代学证据. 第四纪研究, 2009, 29: 574-586

18 四川省地质矿产局. 四川省区域地质志. 北京: 地质出版社, 1991. 306-455

19 Ketcham R A, Donelick R A, Donelick M B, et al. AFTsolve: A program for multi-kinetic modeling of apatite fission-track data. Geol Mater Res, 2000, 2: 1-32

20 李明诚. 石油与天然气运移. 北京: 石油工业出版社, 2004. 1-334

21 郡洁连, 梅建明. 浙江火山岩区金矿床的矿物包裹体标型特征研究及其成因与找矿意义. 矿物岩石, 1986, (3): 1-12

22 刘斌, 沈昆. 流体包裹体动力学. 北京: 地质出版社, 1999. 207-208

23 梁兴中，高钧成. 断裂成矿年龄的 $\alpha$ 石英 ESR 研究. 矿物岩石, 1999, 19: 69-71

24 徐亚军, 杨坤光, 马昌前. 秦岭地区城口-房县断裂带变形特征及 ESR 定年. 现代地质, 2005, 19: 127-132

25 杨奎锋, 杨坤光, 马昌前. 雪峰山安化-涂浦断裂带变形特征及 ESR 定年. 大地构造与成矿学, 2004, 28: 263-269

26 陈衍景, 张静, 张复新, 等. 西秦岭地区卡林-类卡林型金矿床及其成矿时间、构造背景和模式. 地质论评, 2004, 50: 134-152

27 Price N J, Cosgrove J W. Analysis of Geological Structures. Cambridge: Cambridge University Press, 1990. 209-238

28 Brace W, Paulding B W, Schulz C. Dilatancy in the fracture of crystalline rocks. J Geophys Res, 1996, 77: 3934-3953

29 Brown E T, Hoek E. Trends in relationships between measured in situ stress and depth. Int J Rock Mech Min Sci Geomech Abstr, 1978, 15: 211-215

30 Cosgrove J W. Hydraulic fracturing during the formation and deformation of a basin: A factor in the dewatering of low-permeability sediments. Am Assoc Petrol Geol Bull, 2001, 85: 737-748

31 Nadan B J, Engelder T. Microcracks in New England granitoids: A record of thermoelastic relaxation during exhumation of intracontinental crust. Geol Soc Am Bull, 2009, 121: 80-99

32 王学潮, 郭启良, 张辉, 等. 青藏高原东北缘水压致裂地应力测量. 地质力学学报, 2000, 6: 64-70

33 吴满路, 张春山, 廖椿庭, 等. 青藏高原腹地现今地应力测量与应力状态研究. 地球物理学报, 2005, 48: 327-332

34 江在森, 马宗晋, 张希, 等. 青藏块体东北缘水平应变场与构造变形分析. 地震地质, 2001, 23: 337-345

35 安其美, 丁立丰, 王海忠, 等. 龙门山断裂带的性质与活动性研究. 大地测量与地球动力学, 2004, 24: 115-119

36 Hafner W. Stress distributions and faulting. Geol Soc Am Bull, 1951, 62: 373-398

37 姜振学, 庞雄奇, 金之钧, 等. 地层抬升过程中的砂体回弹作用及其油气成藏效应. 地球科学, 2004, 29: 420-427

38 Surdam R C, Jiao Z A, Heasler H P. Anomalously pressured gas compartments in Cretaceous Rocks of Laramide basins of Wyoming: A new class of hydrocarbon accumulation, traps, and the petroleum systems. Am Assoc Petrol Geol Mem, 1997, 67: 199-222

39 郝芳, 邹华耀, 方勇, 等. 断-压双控流体流动与油气幕式快速成藏. 石油学报, 2004, 25: 38-47

40 郝芳, 邹华耀, 龚再升, 等. 新(晚期)构造运动的物质、能量效应与油气成藏. 地质学报, 2006, 80: 424-431 